\title{
Tire strain piezoelectric energy harvesters: a systematic review
}

\author{
Ibrahim Ali Hameed Al-Najati', Keng Wai Chan', Swee-Yong Pung ${ }^{1}$ \\ ${ }^{1}$ School of Mechanical Engineering, Universiti Sains Malaysia, Penang, Malaysia \\ ${ }^{2}$ School of Materials and Mineral Resources Engineering, Universiti Sains Malaysia, Penang, Malaysia
}

\begin{tabular}{l} 
Article Info \\
\hline Article history: \\
Received Jun 16, 2021 \\
Revised Jan 26, 2022 \\
Accepted Feb 2, 2022 \\
\hline
\end{tabular}

Keywords:

Energy harvesters

Intelligent tire

Lead zirconate titanate

Piezo benders

Strain energy

Tire deformation

Tire strain piezoelectric energy harvesters

\begin{abstract}
Intelligent tires are regular tires with additional sensors attached to measure different parameters, such as pressure, temperature, and tire dynamic condition. Sensors mounted inside tires are usually powered by batteries. An alternative power source for these sensors is piezoelectric energy, which uses piezoelectric patches that can be mounted close to the sensors inside vehicle tires. Piezoelectric energy is a battery-less energy source with a long lifespan and environmentally friendly characteristics. This paper presents a comprehensive review of piezoelectric energy harvesters that harvest vehicle tire strain and convert it to electrical energy to power inner tire sensors. The aim of this review was to characterize the possible available tire piezoelectric strain energy harvesters and their advantages and challenges for each type, shape, and material used by researchers so far. The related articles were categorized according to the installation method of the harvester inside the vehicle tire. The four categories are inner tire treadwall, tire bead-rim interface, tire inner sidewall, and tire bead. The maximum power generated was $2300 \mathrm{~mW}$ from a treadwall tire strain piezoelectric harvester. Ten challenges were mentioned and classified into three main groups: host environment, installation method, and scavenging system.
\end{abstract}

This is an open access article under the CC BY-SA license.

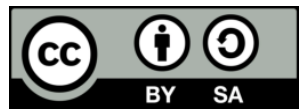

\author{
Corresponding Author: \\ Ibrahim Ali Hameed Al-Najati \\ School of Mechanical Engineering, Universiti Sains Malaysia \\ 14300 Nibong Tebal, Penang, Malaysia \\ Email: ibrahim.hameed@student.usm.my
}

\section{INTRODUCTION}

Tires are an essential part in vehicles because they are the only link between the road and the vehicle [1]. Therefore, the tire monitoring while driving is essential. Piezoelectric materials mounted inside tires can be used as energy source to power tire monitoring systems. Tire strain piezoelectric energy harvesters (TSPEH) are one of the common types used inside vehicle tires. TSPEH scavenge tire strain caused by tire deformation during movement. There is a lack of sufficient knowledge about TSPEH individually. This is because usually researchers consider all energy harvesters that can be mounted inside tires such as piezoelectric vibration harvesters. Hence providing brief information for each harvester type. The significance of this study came from its comprehensive review for TSPEH. In addition, this study categorized the TSPEH according to shape and installing location. Further, TSPEH challenges and suggested enhancements are considered in this work.

Intelligent tires consist of sensors that measure temperature, pressure, tire revolution per minute (RPM), humidity, torque, speed, stress, and strain [2], [3]. One of the crucial components that should be bonded in the tire is the tire pressure monitoring system (TPMS). The TPMS usually mounted inside vehicle tires is a wireless communication safety system used to prevent tire-related accidents by checking tire pressure and temperature and notifying the driver in real time [4]. In the USA, installation of the battery-powered TPMS is mandatory for all new vehicles for safety reasons [5]. The average energy consumption for a typical TPMS is 
$10 \mu \mathrm{j} / \mathrm{rev}$ [6]. Additionally, according to TPMS law federal motor vehicle safety standards (FMVSS 138), the minimum transfer rate for TPMS is one sample for every 10 minutes that consume $60.65 \mu \mathrm{w}$ only [7].

Bowen et al. [8] demonstrated the most common types of energy sources available to power tire condition monitoring systems such as the TPMS. Figure 1 indicates that there various energy sources can be considered as a power source for a TPMS. The piezoelectric energy source is widely used to power the TPMS because the tire environment has high strain/deformation and unused vibration energy. Given the difficulty of connecting the sensors mounted inside the tire with an external energy source (energy source out of the tire), such as car battery, another advantage of using a piezoelectric material is that the piezoelectric harvester is installed inside the tire close to the TPMS location. Currently, about 50 million TPMSs are mounted in new cars every year in the USA [9]. Batteries mounted inside tires have many disadvantages, such as limited lifespan [10] and the environmental waste issue caused by replacing batteries. Moreover, battery-powered TPMSs sense at a low data frequency to save battery energy [11]. The type of energy focused on in the present study is piezoelectric energy harvesters, specifically, piezoelectric energy harvesters that scavenge tire strain energy (tire bending), which is represented in Figure 1.

A simple piezoelectric-powered tire strain piezoelectric energy harvesters TPMS can include five components: i) energy source element; ii) sensor element; iii) other components, such as micro controller, capacitors, and AC to DC current converter; iv) signal transformer element; and v) signal receiver element and data processing unit [12]. The energy source is mounted inside the tire, which in this case is a piezo element that converts tire deformation into electrical current. The sensor element is mounted inside the tire, usually on the wheel close to the energy source, and a number of elements can be added in the same tire to sense various parameters, such as temperature and pressure. A micro controller can be added to the circle to manage energy consumption by shutting down the sensor and the signal transmitter periodically to save energy. Additionally, capacitors are used to store the energy generated because energy production depends on the frequency of tire deformation or tire revolution per minute RPM. The signal transformer element is used to transfer the sensing information from the sensors to the signal receiving unit. The data receiving part transfers sensing data to the data processing unit. Figure 2 shows a simple block diagram of a TPMS circle.

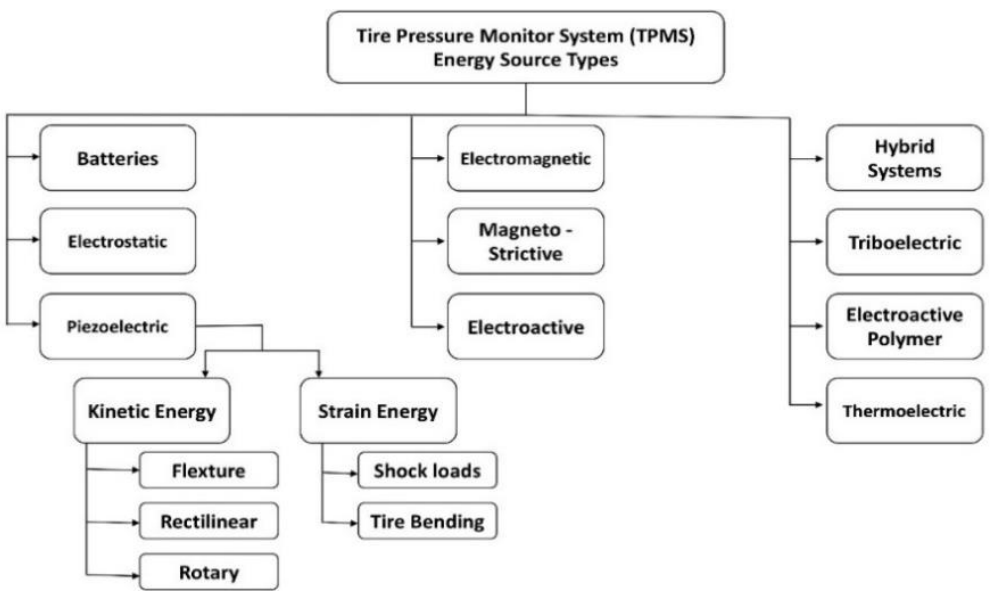

Figure 1. TPMS energy sources' chart according to Bowen and Arafa study [8]

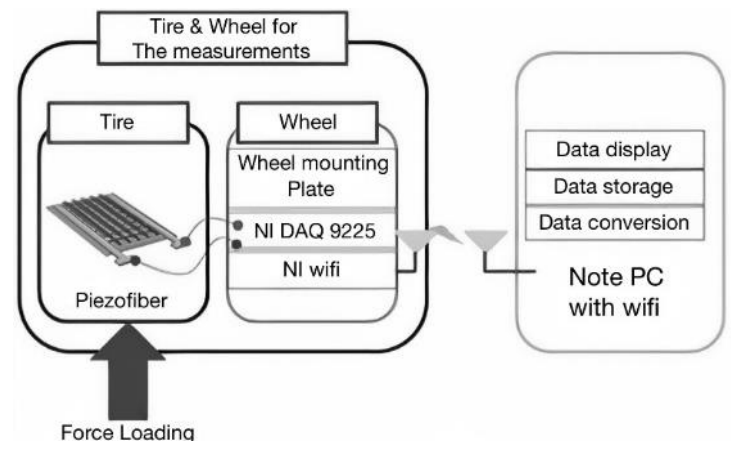

Figure 2. Block diagram of a piezoelectric powered TPMS (reprinted from [1]) 


\section{SYSTEMATIC REVIEW PROTOCOL}

This section shows the systematic review protocol conducted in this research. First, the systematic review method will be presented. Next, search, eligibility criteria, and exclusion criteria will be displayed. Finally, the distribution of results will be illustrated.

\subsection{Method}

The scope is covered by the most current and significant keywords, namely, PEH, piezoelectric material, energy harvester, tire deformation, and tire strain transducer. Furthermore, the scope is limited to english literature. The keywords were mixed to form phrases used to find all related domain articles, for example, "PEH material," "piezoelectric material," and "energy harvester." The full queries used in the databases are presented in Figure 3. Reliable databases were selected for the target articles, including: (i) scopus, (ii) sciencedirect, (iii) web of science (WOS), and (iv) ieee xplore. These databases were selected to cover all the articles relevant to scope of this research.

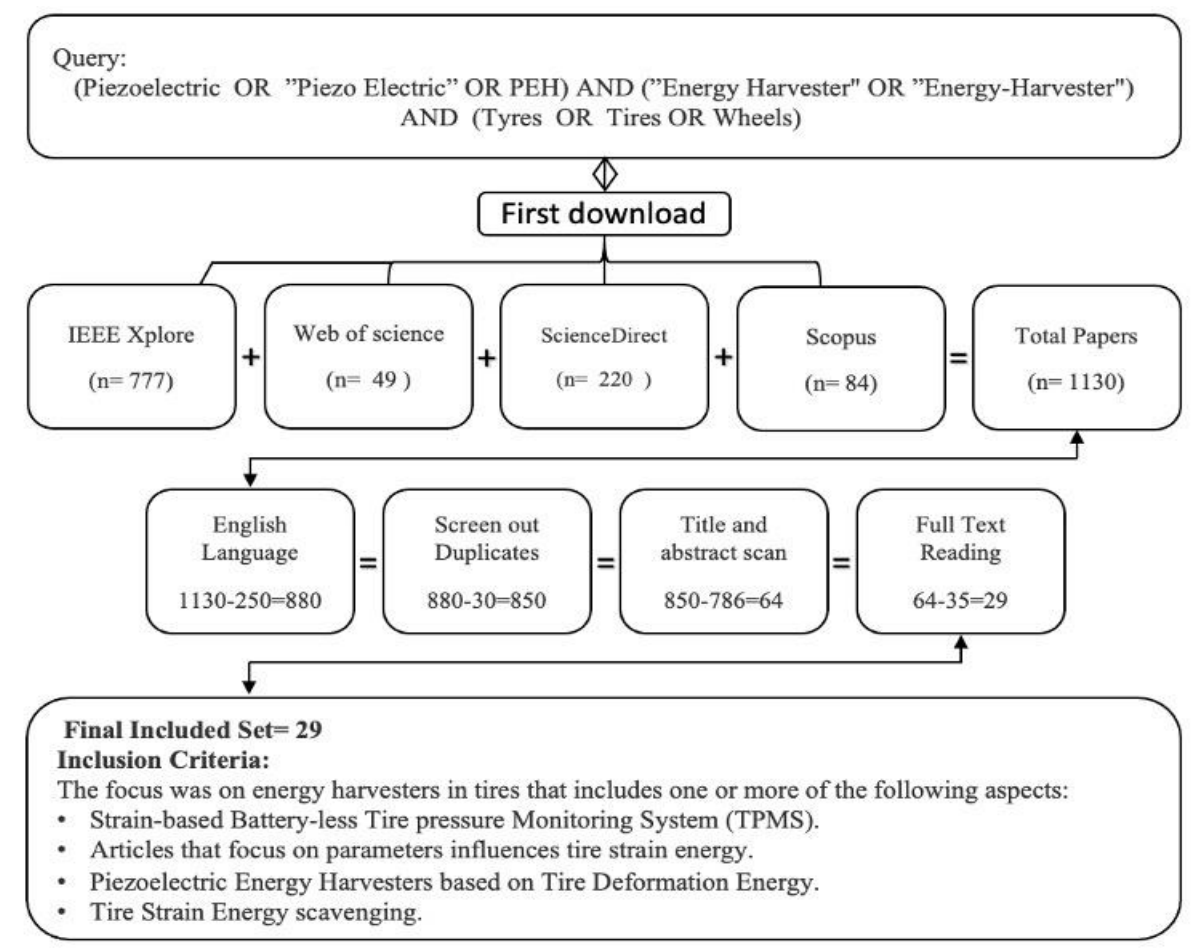

Figure 3. Scientific articles selection flowchart with inclusion criteria

\subsection{Search}

The search query was done after reading various related papers and review articles in the field to identify the common and uncommon keywords used by researchers to define the terms used within the topic of this research. The search was conducted using the search engines for the reliable databases mentioned before. Additionally, a notification alert was set in all databases that searched before in order to consider any new article within the scope of this study.

\subsection{Eligibility and exclusion criteria}

Specific criteria were chosen in this research to include the articles; any article that met the requirement was included in the chosen articles. The first selection criterion was English journal and scientific papers from the reliable resources mentioned above. Second, the piezoelectric energy harvesters used in vehicle tires were focused on a strain energy source that caused by the tire deformation. The study selection included three iterations. The first iteration excluded duplicated articles. The second iteration filtered the out-of-domain articles through reading the title and abstract of the articles. The last iteration excluded the out-of-domain articles through full-text reading of the articles, as shown in Figure 3. 


\subsection{Result distribution}

Figure 4 (a) shows the distribution of 29 scientific papers in the reliable databases, specifically, 13 in web of science WOS, 5 in ieee xplore, and 11 in sciencedirect. A distribution by publication year was done for the final set of papers, as no year filter was set during search process because of the related articles found. Figure 4 (b) shows that the maximum number of publications was in 2019. Another statistical analysis was done to allocate the papers with respect to author nationality. Figure 4 (c) indicates that the maximum number of related articles is from authors of US nationality.

This study has a novel approach in terms of tire strain piezoelectric harvesters (TSPEHs). Note that the term TSPEH has never been used before and is first used in this study to specify future related studies with this novel term. There is no available scientific review paper exclusively describing TSPEHs in full detail. This study also categorizes piezoelectric harvesters into different new categories, such as according to shape and installation method inside the tire. Furthermore, this study takes into account the specific challenges related to TSPEH. Different parameters that affect the energy production efficiency of TSPEH are presented in this paper.

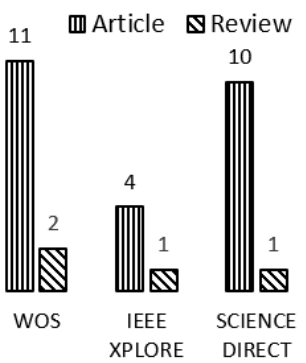

(a)

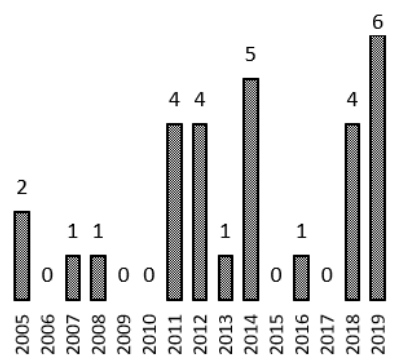

(b)

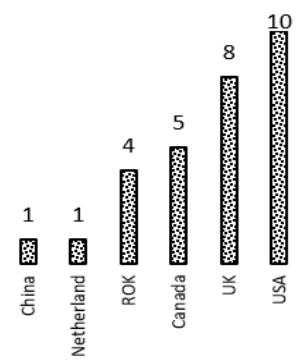

(c)

Figure 4. Results distribution for (a) statistics of papers distribution in indexing databases, (b) distribution by year, and (c) distribution by nationality

\section{THEORY}

The strain resulting from tire deformation transforms to the piezo element attached inside the tire. As a result, a charge distribution change caused inside the piezoelectric material [13]. This charge can be used as energy source for inside vehicle tire monitoring system. In this section, two approaches will be discussed, namely, tire deformation and piezoelectric charge generation.

\subsection{Tire deformation}

Tire strain is produced at the contact patch when a tire deforms under a vertical load. The contact patch is the tire-road interface, which can be divided into three zones: one tension zone at the center of the contact patch $\left(Z_{2}\right)$ and two compression areas at the contact batch boundaries $\left(Z_{1}, Z_{3}\right)$ [7]. Indicating the contact patch region is essential because the piezo element's maximum allowable strain depends on the element length. Additionally, the piezo element length should be equal to the length of the smallest zone in the contact patch [7].

The relation between contact patch length and tire stiffness for a stationary tire can be written as (1) [14].

$$
L_{\text {Patch }}=0.7 Z_{c}\left(\frac{\delta}{Z_{c}}+2.25 \sqrt{\frac{\delta}{z_{c}}}\right)
$$

Where $Z_{c}$ is the unloaded tire radius, and $\delta$ is the tire stiffness. From equation (1), the contact patch length can be found in the range of $165-178 \mathrm{~mm}$ [15]. Tire deformation generates the input strain to the piezo element at the contact patch region. The tire longitudinal strain caused by tire curvature radius is written as (2) [16].

$$
\varepsilon_{\mathrm{z}}=-\frac{\left(\mathrm{z}_{\mathrm{c}}-\mathrm{z}\right)}{\mathrm{R}}
$$

Where $Z_{c}, Z$, and $R$ represent the no-load tire radius from the tire manufacturer, the radius of the inner surface, and the radius of curvature, respectively. The radius of curvature can be calculated from (3) [10].

$$
a=R \cdot \sin \frac{L}{2 R}
$$

Where $L$ is the length of the arc $(R \times \theta), \theta$ is the arc angle, and a is the distance between the two curvature points $\left(\mathrm{r}_{\mathrm{i}-1}, \mathrm{r}_{\mathrm{i}+1)}\right.$ that can be calculated from (4) [10]. 


$$
a=\frac{1}{2} \sqrt{\left(r_{i-1} \sin \frac{\theta}{2}-r_{i+1} \sin \frac{\theta}{2}\right)^{2}+\left(r_{i-1} \cos \frac{\theta}{2}-r_{i+1} \cos \frac{\theta}{2}\right)^{2}}
$$

After the inner liner strain is calculated, the strain applied to the piezo element can be assumed. The strain applied to the piezo bender is $25 \%$ of the tire inner liner [17]. The amount of transferred strain to the piezo element can be affected by many factors, such as stiffness difference between the harvester material and tire material as discussed in the challenges section.

\subsection{Piezoelectric charge generation}

Piezoelectric materials are those that produce charge when compressed or placed under mechanical strain [18], [19]. A basic direct strain piezoelectric harvester can be defined as a piezoelectric material in a parallel plate configuration that represents a $d_{31}$ effect [20]. It is assumed that the piezoelectric element does not affect tire stiffness, and therefore the charge output in this case can be represented in (5) [20].

$$
Q=\frac{d_{31} S w l}{s^{\mathrm{D}}}
$$

Where $d_{31}, S, w, 1$, and $s^{D}$ represent the piezoelectric charge constant, applied strain, device width, device length, and a mechanical compliance under short circuit conditions, respectively. An interdigitated electrode transducer (IDE) configuration can be employed to benefit the larger longitudinal piezoelectric constants $\left(\mathrm{d}_{33}\right)$ of the piezoelectric materials along the transverse direction of the device. In this setup, the total charge output can be calculated from (6) [20], [21].

$$
Q=\frac{-(n-1) d_{33} S w t}{s^{D}}
$$

Where $\mathrm{n}, \mathrm{d}_{33}$, and $\mathrm{t}$ are the number of electrodes, piezoelectric charge constant, and thickness of the energy harvesting device, respectively. At distance $\mathrm{x}$ from the terminal ends, the local accumulated charge for the piezoelectric material can be calculated by (7) [7].

$$
Q(x)=-(n-1) d_{33} Y_{33} \varepsilon(x) w t
$$

Where $\mathrm{Y}_{33}$ is young's modulus of elasticity for piezoelectric harvester. The total accumulated charge over all piezoelectric transducers is to [7]:

$$
Q=-(n-1) d_{33} Y_{33} w t \int_{0}^{L} \frac{\varepsilon(x)}{L} d x
$$

Where $\mathrm{L}$ is the effective length of the piezoelectric element. The electrical charge per tire revolution can be calculated using the strain calculated from equation (2) and fed into equation (8). Additionally, due to the rectification process, equation (8) should be applied twice for loading and unloading each zone $\left(\mathrm{Z}_{1}, \mathrm{Z}_{2}\right.$, and $\left.\mathrm{Z}_{3}\right)$ as seen in Figure 5.

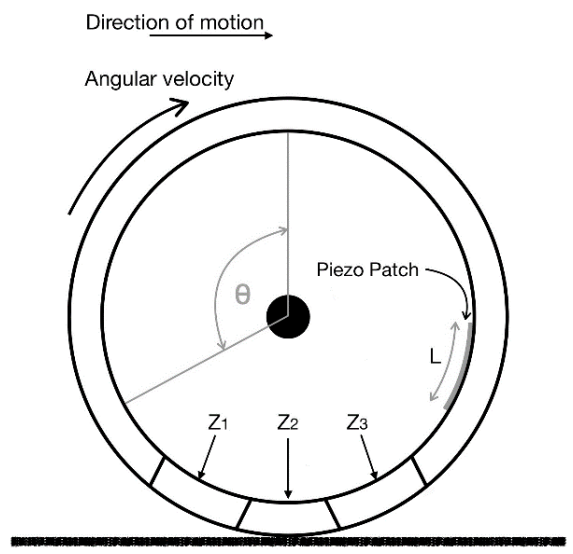

Figure 5. Tire contact patch regions [7] 


\section{TIRE STRAIN HARVESTER SHAPES}

Piezoelectric materials have the benefit of exhibiting high performance and being available in a wide range of shapes [22]. Five piezoelectric energy harvester shapes were fabricated in the past, specifically, rectangular, square, circular, rainbow, and cymbal shape as shown in Figure 6 . The most commonly used one is the rectangular shape; this is because when a force is applied, the rectangular shape allows more bending compared to other piezo shapes. A higher bended piezoelectric produces more energy. Choosing the suitable harvester shape depends on some criteria, such as installation location, type of piezo element material, method of stacking the harvester on the host, working environment conditions, and amount of power/energy desired to be transduced. For example, a square shape element is preferable to use when a high host deformation exists while a rectangular element is more suitable to install with less deformation applied.

Although a rectangular shape transducer is most commonly used as a tire strain piezo harvester, it would seem that the circular shape element can be more favorable to harvest tire strain energy. This is because the circular shape generates the maximum energy from tire deformation compared to other shape elements. Additionally, using an aluminum reinforcement plate glued to the circular piezo can enhance the piezoelectric mechanical properties, such as increasing the allowable deformation the element can withstand before failure. Figure 7 represents the distribution of each tire strain piezoelectric energy harvesters TSPEH shape used in literature.
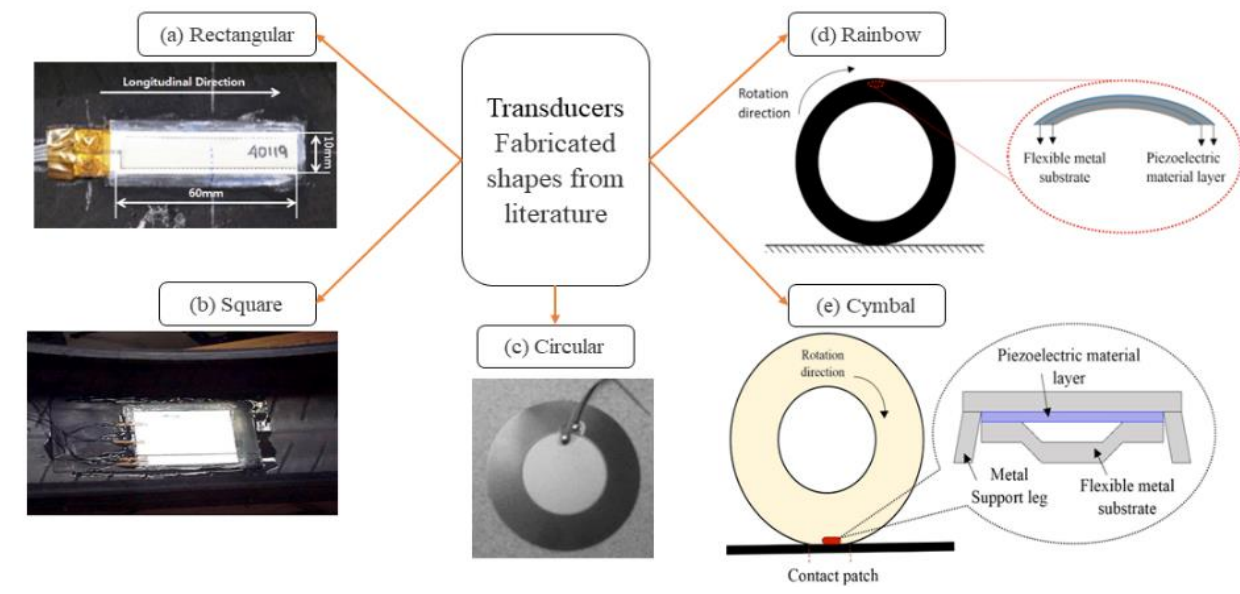

Figure 6. Tire strain transducers' shapes found in literature (a) reprinted from [1] (b) reprinted from [23] (c) reprinted from [24] (d) reprinted from [25] and (e) reprinted from [26]

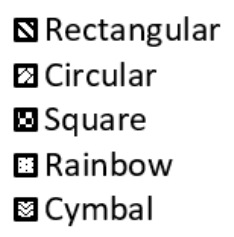

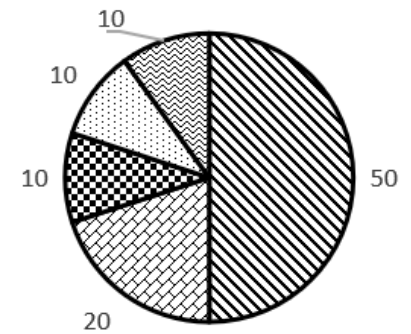

Figure 7. The distribution of TSPEHs according to shape in literature

\section{TIRE STRAIN PIEZOELECTRIC HARVESTERS}

The wasted deflection energy in a vehicle tire is estimated to be more than $1 \mathrm{kWh}$ [27]. This amount of unused energy is high compared to other energy sources, such as vibration energy. This section describes the types of tire strain piezoelectric energy harvesters TSPEHs that were categorized according to their installation location inside the vehicle tire. First, a treadwall tire strain energy harvester is explained. Second, the tire bead-rim interface is represented. Next, sidewall tire strain energy is shown. Finally, a strain energy mounted in a tire bead is described. Note that this categorization was performed according to a literature review that was made for related articles. Figure 8 represents the TSPEH taxonomy indicating the four categories of 
TSPEH applications. The taxonomy was also categorized according to the TSPEH installation place inside the vehicle tire, namely, inner tire treadwall, tire bead-rim interface, tire inner sidewall, and tire bead.

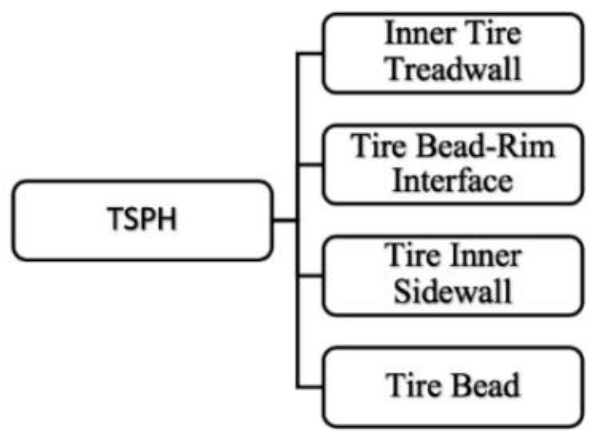

Figure 8. TSPEH research taxonomy on tire bending scavenging applications

\subsection{Inner tire treadwall strain energy harvesters}

Strain energy harvesters mounted to the inner tire treadwall has many advantages. The inner tire treadwall is the most common place to mount harvesters in a vehicle tire due to high energy strain. Additionally, the installation process for TSPEH in this location in the vehicle tire is not very complicated because it only requires an adhesive material to adhere the transducer inside the tire inner liner. However, this installation approach may cause some issues; for example, the TSPEH might be damaged due to tire punctures. The difficulty of replacing the glued damaged TSPEH is another factor that should be taken into account. One of the first attempts to harvest tire strain energy was conducted by the Apollo project in 2005 [23]. The maximum energy produced was $0.9 \mathrm{~mW}$ using an $80 \mathrm{~mm} \times 80 \mathrm{~mm}$ square sheet of polyvinylidene fluoride (PVDF) with a $3.9 \mathrm{kN}$ and $80 \mathrm{~km} / \mathrm{h}$ operation condition. However, the Apollo project shows that PVDF is not suitable for the tire environment because of tire high temperature and strain energy. It is likewise difficult to avoid overload damage in the piezo material owing to the large strain applied to the piezoelectric harvester.

Using a wireless strain gauge system, Lee et al. [6] presented the amount of longitudinal and lateral strains at different setups of pressure, load, and RPM. They reported that the total strain value increased when the applied load increased significantly. In the same manner, the result indicated that the strain shows a slight increase when the speed increases, and pressure influences the effect of applied load on the resulting strain. At $152 \mathrm{kPa}$ pressure, an increasing applied load leads to a gradual increase in lateral strain, which increases independently when increasing the load at $234 \mathrm{kPa}$ pressure. Scavenging the lateral strain mentioned above can produce $0.58 \mathrm{~mJ}$ energy at $40 \mathrm{~km} / \mathrm{h}$ speed, $600 \mathrm{k} \Omega$ resistance, and $4.9 \mathrm{kN}$ load. Lee et al. [6] reported that harvesting the available longitudinal strain stated above would produce three times the energy value. However, in the present study, the rectification process reduces the energy to a third of the value. Thus, the rectification process should be improved to minimize energy losses.

A piezoelectric composite with interdigitated electrodes and substrate was developed by Lee et al. [1]. Using a piezoelectric patch of $60 \times 10 \times 0.3 \mathrm{~mm}^{3}$, a maximum energy of $380.2 \mu \mathrm{J}$ and power density of 1.37 $\mu \mathrm{W} / \mathrm{mm}^{3}$ was produced under $4.9 \mathrm{kN}$ and $60 \mathrm{~km} / \mathrm{h}$. Furthermore, two capacitors were used that charge one after another to supply a constant voltage of $3 \mathrm{~V}$ using a regulator. However, the circuit efficiency was no more than $9.7 \%$ which can be enhanced by reducing capacitor leakage and impedance matching. Another solution might decrease the number of capacitors and, at the same time, increase piezoelectric patch dimensions. Another study was conducted by Lee et al. [10], who studied the effect of vehicle load and velocity on tire radius change. They found that at a load range of $2.94-6.86 \mathrm{kN}$ with a constant velocity of $60 \mathrm{~km} / \mathrm{h}$, the radius change equals $34.3 \mathrm{~mm}$. However, the radius change was less than $1 \mathrm{~mm}$ with a vehicle velocity range of $30-90 \mathrm{~km} / \mathrm{h}$ while the load was equal to $4.9 \mathrm{kN}$ constant value. On one hand, vehicle load has a significant effect on tire deformation change. On the other hand, the vehicle velocity has a minor effect on the tire deformation change. Therefore, the vehicle velocity was neglected in this study. Lee et al. [1] showed a maximum energy of $380 \mathrm{~mJ}$ with a power density equal to $4.05 \mathrm{~mW} / \mathrm{mm}^{3}$ under a $4.4 \mathrm{kN}$ load and a speed of $60 \mathrm{~km} / \mathrm{h}$ using a piezoelectric materials lead zirconate titanate (PZT)-5H piezoelectric patch with dimensions of $60 \mathrm{~mm}(\mathrm{~L}) \times 14 \mathrm{~mm}(\mathrm{~W}) \times 0.8 \mathrm{~mm}(\mathrm{H})$. However, not all available strains were scavenged by TSPEH due to limited adhesive flexibility because the scavenged strain were reduced to about $25 \%$ of the total strain available in the tire inner liner. A more strain can be harvested by using a more flexible adhesive. In the same manner, the adhesive needs to meet other requirements, such as long lifespan and wide range of operating temperature. 
An extensive study was initiated by Makki et al. [24], who measured the deformation frequency for a $140 \mathrm{~mm}$ contact patch (road-tire interface area) at different vehicle speeds. They found that at least $8 \%$ of the total treadwall area is deformed at any time during tire rotation. The Lead Zirconate Titanate PZT material was then chosen by applying different criteria, such as power efficiency, flexibility for 540 million cycles, and cost. Due to high tire deformation, PZT material might not be reliable for such application. To solve this issue, Makki et al. [24] bonded a circular PZT element to a rectangular and a circular brass substrate. The brass element reduces the available treadwall area and, consequently, reduces the total number of elements that can be mounted inside the tire treadwall. Adhesive was also applied to the center line of 40 rows with 4 elements each of PZT benders to protect the PZT benders from damage. This application might decrease the deformation applied to the PZT benders and thus reduce the generated energy. The authors stated that the power can be increased when increasing three aspects, namely, piezo bender end-to-end deflection, inner tire treadwall surface area, and tire RPM. Using double-layer PZT benders stacked on a rubber sheet that covers all the tire inner circumference, the study theoretically shows that $4.6 \mathrm{~W}$ can be produced at a vehicle speed of $100 \mathrm{~km} / \mathrm{h}$. In the experiment, the produced power was as high as $2.3 \mathrm{~W}$. The results of the study represent the maximum energy produced from a piezoelectric energy harvester mounted in a vehicle tire. Therefore, theoretically, this produced energy can power tire sensors and other vehicle equipment, such as headlamps with a prober electric circuit design and added controller, as well as using all available space inside the tire to mount the transducer material.

Through later developments, Makki et al. [28] fabricated a four PZT bender $25 \times 38 \mathrm{~mm}$ in size and reinforced by a brass element that generates $6.5 \mathrm{~mW}$ power with matching resistance equal to $42 \mathrm{k} \Omega$. Additionally, with a capacitor of $61 \mu \mathrm{F}$, transmission frequency increased from every $2.5 \mathrm{~s}$ to every $1.5 \mathrm{~s}$ when the tire velocity increased from $60 \mathrm{~km} / \mathrm{h}$ to $100 \mathrm{~km} / \mathrm{h}$. Using a microcontroller to power circular components through a selective method also reduced the power consumption significantly. Another strength of this study is that it used a PZT ceramic that costs 1 USD per element ( $25 \mathrm{~mm}$ diameter). This is a sound approach because it encourages companies to use PZT as a TSPEH for mass production instead of a battery-powered tire strain piezoelectric energy harvesters TPMS. In the same study, Makki et al. [28] assumed that vehicle weight has no effect on output power. This is a problematic assumption because Makki et al. [29] and other researchers found that vehicle weight influences output power significantly by effecting tire deformation as stated above.

In another study, to resolve the limitations of piezo bender deflection, Makki et al. [29] demonstrated the use of a $25 \mathrm{~mm}$ diameter PZT circular plate glued inside a tire that produced a deflection as high as $9 \mathrm{~mm}$ without shape damage. This result was due to the reinforcement of a $0.23 \mathrm{~mm}$ thick brass element that stacked to the PZT as well as the use of a highly flexible adhesive material. It is important to note that the circuit board was bonded to the back of the piezo bender, which can cause damage to both circuit board and piezo element owing to the high strain input caused by tire deformation. Correspondingly, adhering the electrical circuit to the back of the piezo bender may limit the piezo bender flexibility. The testing results showed that a $0.11 \mathrm{~mm}$ thick of $40 \times 40 \mathrm{~mm}^{2}$ square PVDF element could produce a peak voltage of $62.3 \mathrm{~V}$ with no load. Likewise, a maximum power of $0.85 \mathrm{~mW}$ was produced from PVDF at a load resistance of $380 \mathrm{k} \Omega$ and a speed of $9 \mathrm{~km} / \mathrm{h}$, lower than the $4.6 \mathrm{~mW}$ power extracted using a PZT element with a load resistance of $46 \mathrm{k} \Omega$ under the same working environment. Despite the low energy produced by PVDF, it is more suitable for high strain environments such as vehicle tires. PVDF also has minimum impact on tire deformation patterns due to its high flexibility.

Later in 2012, Makki et al. [30] reduced the sensor operation time from $90 \mathrm{~ms}$ (in a previous study) to $31 \mathrm{~ms}$. In addition, using an oscilloscope, they tested the charging and discharging time for different size capacitors in terms of $10 \mathrm{~V}$ charging voltage. They proposed that charging a $22 \mu \mathrm{F}$ capacitor requires 9 tire revolutions while charging a $47 \mu \mathrm{F}$ capacitor requires 17 revolutions. Reducing the sensor operating time leads to a quicker transfer of sensing information to the vehicle driver. At the same time, increasing the electrical circuit efficiency of the TPMS would provide more energy that can power more sensors inside the vehicle tire.

Ende et al. [11] proposed that a maximum of $30 \mu \mathrm{W} / \mathrm{cm}^{2}$ can be produced with a $40 \times 16.5 \mathrm{~mm}^{2}$ active area. The material used was short PZT fibers (SFC10) that was structured using the dielectrophoretic (DEP) process. Despite all the test runs being conducted in the same environment conditions, this result was found using an inflated tire due to the lack of considering the influence of tire pressure on the final results. This is because tire pressure might affect tire deformation, and so the results might be inaccurate. In another study, Ende et al. [20] developed three types of piezoelectric composites by adding different structures of PZT particles. In detail, the three composites are PC10 (with uniform PZT elements), SPC10 (with a chain-like PZT structure using the DEP process), and SFC10 (with short-fiber PZT-5A using the DEP process). The maximum power was $8 \mathrm{~mW}$ with $50 \mathrm{~km} / \mathrm{h}$ vehicle speed when using the SFC10 as core harvester material. However, these piezoelectric patches were not installed in a real vehicle tire to examine the effect of the host environment on the energy produced by the transducer.

A rainbow-shaped piezoelectric transducer constructed from two flexible metal substrates and two piezoelectric material layers was assembled by Esmaeeli et al. [25] that bonded in the inner tire treadwall. One 
of the most common advantages of a rainbow-shaped piezo transducer is multi-direction deformation scavenging, whereas traditional plain structure piezo benders usually harvest one-direction deformation. Furthermore, the influence of piezo width on the output power and energy produced was conducted using a 23 $\mathrm{mm}$ piezo material length of $0.2 \mathrm{~mm}$ thickness. The result showed that increasing piezo bender width from 2.5 $\mathrm{mm}$ to $8 \mathrm{~mm}$ caused an increase in the values of output energy, power, and energy efficiency from $0.69 \%$ to $8.3 \%$. The authors demonstrated that this energy harvester can produce $95 \mu \mathrm{J} / \mathrm{rev}$ energy and $5.85 \mathrm{~mW}$ power. In other words, the harvester can power three sensors with a transmission rate of $30 \mathrm{pulse} / \mathrm{min}$. However, the maximum displacement for the rainbow-shaped piezo bender was not measured to indicate the compatibility of this piezo shape with the high deformation tire's environment.

In another study of the same research group, Aliniagerdroudbari et al. [26] fabricated a PZT cymbal piezo bender bonded to a flexible aluminum metal substrate with dimensions of $10 \mathrm{~mm}$ length, $0.5 \mathrm{~mm}$ thickness, and $5 \mathrm{~mm}$ width. This tire strain piezoelectric energy harvester shape has many advantages, such as conversion of radial displacement to a longitudinal one $\left(d_{31}\right.$ and $d_{33}$ approach influence strain energy scavenging) due to the gap located in the cymbal harvester. In addition, they demonstrated that this design is simpler and easier to fabricate compared to other similar harvesters. It was found that this design can generate $90 \mu \mathrm{J} / \mathrm{rev}$ energy and $5 \mathrm{~mW}$ power at a tire speed of $41 \mathrm{~km} / \mathrm{h}$ and $4.9 \mathrm{kN}$ load. Even so, the durability of this design was not tested during real tire driving conditions, such as wide temperature difference and high vibration environment.

Later in 2019, Esmaeeli et al. [31] demonstrated that using a $23 \mathrm{~mm}$ long, $0.2 \mathrm{~mm}$ thick, and $2.5 \mathrm{~mm}$ wide rainbow-shaped piezo harvester could produce $95 \mu \mathrm{J} / \mathrm{rev}$ energy and $5.85 \mathrm{~mW}$ power at $41 \mathrm{~km} / \mathrm{h}$. They also suggested that a rainbow-shaped tire strain piezoelectric energy harvesters can generate 16 times more energy than vibration-based energy harvesters. The rainbow-shaped harvester consists of two piezo materials and two flexible metal substrates sandwiched together such that no motion can occur. Esmaeeli et al. [31] suggested that the designed rainbow harvester can power nine TPMSs that consume $10 \mu \mathrm{J} / \mathrm{rev}$ each. However, an investigation into essential parameters, such as contact patch optimum dimensions and maximum service strain for the tested harvester, was lacking.

Esmaeeli et al. [15] explored a cymbal-shaped harvester made of PZT-5H piezoelectric material and two steel elements. A cyanoacrylate adhesive was used to bond the tire strain energy harvester inside the tire. Strain applied to the piezo material inside the tire was reduced to a quarter of the tire strain owing to the adhesive material's high stiffness. The result also shows that increasing tire air temperature from $23{ }^{\circ} \mathrm{C}$ to $50{ }^{\circ} \mathrm{C}$ leads to an increase in produced energy from $24.4 \mu \mathrm{J} / \mathrm{rev}$ to $26.5 \mu \mathrm{J} / \mathrm{rev}$, which is sufficient energy to power two tire pressure monitoring system TPMSs. Increasing temperature leads to an increase in the stiffness of steel elements, allowing the cymbal harvester to bend more and produce more energy. The power generated was 2.8 $\mathrm{mW}$ with a voltage of $3.5 \mathrm{~V}$. However, temperature increase beyond the piezo Curie temperature may cause permanent damage to the harvester. In addition, the adhesive material used was not suitable for this experiment setup. The adhesive reduced the tire deformation strain to equal $25 \%$ of the original strain delivered to the transducer. Reducing the tire strain to a quarter of its original value might also affect the tire deformation flexibility, possibly leading to safety issues.

High-power density and high temperature stability harvester were achieved by Maurya et al. [32] using a flexible organic PVDF. Additionally, the influence of vehicle speed on the produced voltage was utilized. Increasing the vehicle speed from $48 \mathrm{~km} / \mathrm{h}$ to $112 \mathrm{~km} / \mathrm{h}$ causes an increase in the produced voltage because the increase in tire speed leads to an increase in the frequency of harvester bending, thereby increasing the voltage generated. In the same manner, the authors emphasized that piezo material thickness is another factor that influences voltage. Specifically, they suggested that increasing piezo material thickness leads to an increase in the generated voltage. Using a $2 \mathrm{~mm}$ thick piezo material causes a marginal drop in the voltage value. The experimental result shows that the fabricated piezo harvester can power 78 LEDs by using the generated power equal to $580 \mu \mathrm{W}$ at $16 \mathrm{~Hz}$ or $112 \mathrm{~km} / \mathrm{h}$.

Kubba et al. [7] developed a flexible piezoelectric fiber composite transducer mounted inside the tire treadwall. To find the best location for the harvester inside the tire, they simulate tire behavior to find the amount of strain produced in the contact patch region (tire-road interface). The result shows that the maximum strain occurs in the middle of the contact patch area for a free rolling loading condition while the strain reduces at the contact region boundaries. Furthermore, Kubba et al. [7] investigated the influence of braking, rolling, and traction loading condition on the contact patch strain. The results imply that maximum strain occurs under the traction condition. In the same manner, the optimum energy found was $48.545 \mu \mathrm{J} / \mathrm{rev}$ with a power of 81.6 $\mu \mathrm{W}$ using a $1000 \mu \mathrm{F}$ storage capacitor at $10 \mathrm{~km} / \mathrm{h}$ rolling speed.

In the effort of scavenging strain energy for nanoscale harvesters, Hu et al. [33] demonstrated the use of a cantilever nanogenerator (NG) consisting of five layers: flexible polyester, substrate material, $\mathrm{ZnO}$ nanowire, and two textured films that cover the NG from top and bottom. Note that despite this cantilever NG scavenging the strain energy, most other cantilever structures harvest vibration energy only. Owing to the 
uncomplicated experiment setup, the NG was mounted in a bicycle tire with an effective working area of about $1.5 \times 0.5 \mathrm{~cm}$. The authors indicated that a calculator LCD screen can be powered by the NG, which produced a power density of $70 \mu \mathrm{W} / \mathrm{cm}^{-3}$ and a current of $25 \mathrm{nA}$ with an acceleration equals to $30 \mathrm{~ms}^{2}$. In the same manner, they described the possibility of connecting multiple NGs in parallel that approximately double the resultant power. They also suggested that $50 \mathrm{~W}$ can be produced if the NGs cover the entire inner space of the vehicle tires. To understand how vehicle speed influences the generated voltage, some extra test runs were implemented. It was reported that output voltage rose when the vehicle speed increased. After recent studies associated with harvesters installed in the tire treadwall were reviewed above, the Table 1 presents all the power generation and energy comparison related to tire treadwall installation methods.

Table 1 clearly shows that for treadwall-mounted transducers, the maximum power generated was $2300 \mathrm{~mW}$ by Makki et al. [24], who considered large-scale piezoelectric energy harvesters that used PZT material. Moreover, the minimum power generated in this category was equal to $0.0525 \mathrm{~mW}$ for the $\mathrm{ZnO}$ harvester fabricated by $\mathrm{Hu}$ et al. [33]. The Table 1 cannot be used as an indicator for the best energy-efficient piezoelectric material. This is because the number of piezo elements installed in the experiment is different from one study to another. The piezo element sizes used are different as well. Moreover, the working condition varies for each experiment, such as applied vertical load and tire RPM. Table 1 could be beneficial in terms of gaining a general knowledge about the range of energy produced for treadwall-mounted harvesters.

Table 1. literature review comparison in terms of treadwall mounted TSPEH power generation

\begin{tabular}{ccccc}
\hline Material & Element Dimension $(\mathrm{mm})$ & Power $(\mathrm{mW})$ & Energy $(\mathrm{mJ})$ & Ref. \\
\hline PVDF & $80 \times 80$ & 0.9 & - & {$[23]$} \\
PVDF & $40 \times 40$ & 0.85 & - & {$[29]$} \\
Organic PVDF & $20 \times 8$ & 0.58 & - & {$[32]$} \\
PZT & 25 diameter $(4 \times 38$ array $)$ & 2300 & - & {$[24]$} \\
PZT & $25(4$ discs $)$ & 6.5 & - & {$[28]$} \\
PZT & 25 (diameter & 4.6 & - & {$[29]$} \\
PZT & $23 \times 8$ & 5.85 & 0.095 & {$[25]$} \\
PZT & $10 \times 5$ & 5 & 0.09 & {$[26]$} \\
PZT & $23 \times 2.5$ & 5.85 & 0.095 & {$[31]$} \\
PZT-5H & $9($ diameter & 2.8 & 24 & {$[15]$} \\
PF & $132 \times 14 \times 0.3$ & 1.5 & 0.58 & {$[6]$} \\
PFC & $132 \times 10 \times 0.375$ & 0.0816 & 0.0485 & {$[7]$} \\
PC & $60 \times 10 \times 0.3$ & 0.2466 & 0.3802 & {$[1]$} \\
PC & $60 \times 14 \times 0.8$ & 2.7216 & 380 & {$[10]$} \\
SFC10 & $40 \times 16.5$ & 0.198 & - & {$[11]$} \\
SFC10 & $200 \times 200$ & 8 & - & {$[20]$} \\
SPC10 & $200 \times 200$ & 0.1 & - & {$[20]$} \\
ZnO & $0.15 \times 0.05$ & 0.0525 & - & {$[33]$} \\
\hline
\end{tabular}

\subsection{Tire bead-rim interface strain energy harvesters}

This installation method allows the harvester's circuit to be mounted on the wheel rim (inside the tire and close to the harvester), which would reduce the number of wire connections. Furthermore, this installation approach can be used at the same time when using the inner tire treadwall method (which can be used as an additional energy-harvesting method). Although the tire bead-rim protects the piezo element from tire punctures caused by external objects, this type of installation method consists of various drawbacks. First, the installation process might be difficult compared to the tire inner treadwall installation technique. Tire air pressure may also decrease due to air leakage caused by place of piezo element installation. Lastly, no durability information is available for the harvesters that used in this installation method.

A novel approach conducted by Makki et al. [28] used a very slim piezoelectric materials PZT element installed between the tire bead-rim interface. The working principle was based on air tire pressure that forced the tire bead uniformly to the rim. This force increased above the contact patch region due to the high deformation of the sidewall over the contact patch. Therefore, if a thin film of piezoelectric harvester was placed between the tire bead-rim interface, then electric power would be generated due to the strain applied on the harvester element. In the same study, Makki et al. [28] found that $70 \mu \mathrm{W}$ could be generated when applying $67 \mathrm{k} \Omega$ matching resistive load. However, this power is considered a very low value compared to the $6.5 \mathrm{~mW}$ generated from a treadwall piezoelectric energy harvester in the same report. Additionally, the tire bead-rim PZT takes about 240 tire revolutions to charge capacitors with $10 \mathrm{~V}$ while traditional treadwall-mounted harvesters reach the same voltage after only 9 revolutions.

In another study conducted by Makki et al. [30], same tire bead-rim installation method was used. One of the main points highlighted in the research is that the PZT element should be no more than $8 \mathrm{~mm}$ wide to fit within the tire bead-rim interface. Some factors also influence generated power, such as tire RPM, inflation pressure, piezo element area, and vertical load. The main finding was that $10 \mathrm{~V}$ charged a $22 \mu \mathrm{F}$ 
capacitor after $200 \mathrm{~s}$ at $80 \mathrm{RPM}$. In terms of maximum element width set in this study, it is advised according to the study's experiment setup and might not be suitable for all different tests. The optimum harvester width depends on the tire size; for example, some studies mounted harvesters inside much smaller tires such as bicycle tires. Furthermore, harvester width depends on the piezoelectric material type used; for example, the PZT material can be produced with small sizes because of flexibility limitations. Figure 9 (a) represent the thin PZT element with the electrical circuit connection. Further, Figure 9 (b) characterize the final installation shape inside vehicle tire. Additional, Figure 9 (c) shows a 2D sketch for the piezo element between the tire and the rim.

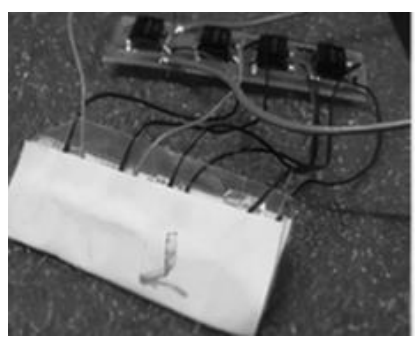

(a)

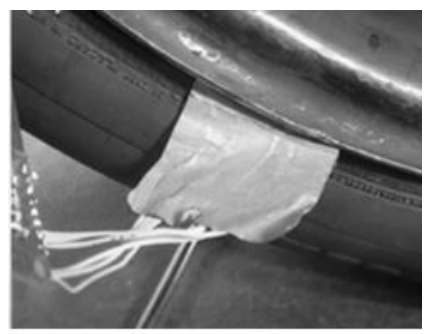

(b)

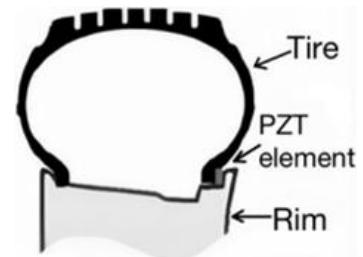

(c)

Figure 9. Tire bead-rim installation method in where (a) very thin PZT, (b) final installation of the PZT, and (c) installation place of the PZT (reprinted from [30])

\subsection{Tire inner sidewall strain energy harvesters}

In terms of side wall tire deformation, it can reach strains in the range of 10-50 $\mathrm{mm}$ [34]. This is considered to be a very high amount of deformation that should be scavenged. Furthermore, the installation process is not difficult for this approach since it requires a piezo element and an adhesive material to be mounted on the tire inner sidewall. However, this approach has fewer experiments compared with other installation methods. Another issue is that there is a safety concern with this installation type because it directly affects the tire deformation. Finally, replacing the damaged piezo element is difficult because it is glued to the tire inner sidewall. An effort was made by Makki et al. [24] to conduct a sidewall PZT harvester. However, this attempt was not successful due to the high deformation environment and limited PZT flexibility. In the same manner, they recommend using a polyvinylidene fluoride PVDF material for such application. However, a safety concern may arise since the tire deformation is mainly based on sidewall deformation.

Using a mathematical sensor model, Moon et al. [5] proposed that a strain-based PVDF sensor can be used to indicate tire deformation by measuring the generated charge. The fabricated PVDF with dimensions of $20 \times 3 \times 0.1 \mathrm{~mm}^{3}$ and $110 \mu \mathrm{m}$ thickness was mounted in two places inside the tire. The first method was gluing the PVDF sensor inside the tire treadwall to measure tire bending. Second, the second sensor was clamped from both ends to the tire sidewall to measure the tire buckling. With the use of a laser deflection sensor, the laboratory result shows a good agreement between the measured deformation and the deformation found from the PVDF charge sensing. However, some limitations of the working conditions exist. For example, the range of tire deformation on which this method is still valid, were not discussed. Lack of charge losses information in the circle that may affect the measurement efficiency were not discussed as well.

\subsection{Tire bead strain energy harvesters}

A previously discussed study conducted by Makki et al. [29] used a plastic ribbon fixed to the tire rigid bead from both ends. Furthermore, PVDF piezo elements were bounded to that plastic ribbon. The ribbon deformation method was based on the difference in tire section width and height that was caused by cyclic tire rotation. The maximum power generated was $0.23 \mathrm{~mW}$ with a $400 \mathrm{k} \Omega$ and $80 \mathrm{RPM}$ as well as a peak voltage of $18.7 \mathrm{~V}$. This experiment was significant in terms of illuminating any tire safety concerns because the 
piezoelectric harvester is not attached to the tire surface. Figure 10 represents the tire bead energy harvester method. Makki et al. [29] study is the only one to have conducted this type of harvester inside a vehicle tire, this installation method has some advantages compared to other methods. First of all, this ribbon has less effect on tire deformation because it does not attach to it. Second, the replacement process of the plastic ribbon is much easier compared to the tire treadwall-mounted harvester. Furthermore, many piezo elements can be on a single plastic ribbon. It is also less possible for the piezo element to be damaged by punctures owing to the space between the tire and the plastic ribbon. However, the durability of this installation technique was not tested.
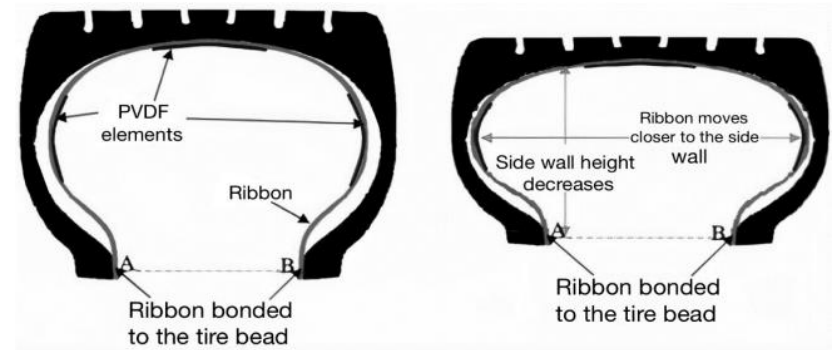

Figure 10. Change in tire section width and height that cause ribbon deformation (reprinted from [29])

\section{PARAMETERS THAT INFLUENCE TIRE DEFORMATION}

To investigate camber angle influence on the contact patch's longitudinal and lateral strain, Yunta et al. [35] exploited a number of strain sensors installed in different positions inside a tubeless tire. They indicated that the camber angle (equal to $5^{\circ}$ in the experiment), which is the angle between the tire longitudinal plane and the plane that is vertical on the road, has a significant influence on tire deformation. They likewise pointed out that the inflation pressure has less influence on strain results compared to the vertical load effect. With respect to electrical wire connections, during the experiment, some issues were raised and reported by Yunta et al. First, the electrical solder joints of the strain sensors were damaged due to centrifugal force causing some data collection problems. Second, since the tubeless tire was inflated, it was difficult to connect the sensors located inside the tire to the computer outside the tire. This issue was solved by making a hole in the rim to place the data acquisition DAQ. However, despite the weight being no more than $80 \mathrm{~g}$, it may cause extra vibration in the tire rim that leads to an error in the measurements. This drawback can be solved by rebalancing the tire after putting the data acquisition DAQ in the rim.

Pozuelo et al. [36] explored a simulation and experimental study to measure tire strain with different applied parameters, such as inflation pressure and applied vertical load. Under loads of $500 \mathrm{~N}$ and $5000 \mathrm{~N}$ and an inflation pressure range of 1.2-2.6 bar, the longitudinal strain was found to be much higher than the lateral strain produced by the tire. The result shows that both radial and tangential strains were approximately identical when applying small vertical load. By applying a braking longitudinal force and $3000 \mathrm{~N}$ vertical load, the deformation shifts to the braking force direction. Another tire laser sensor developed by Aalto University was used in this study. The laser sensor consisted of a 1-D laser triangulation system and was mounted to the tire rim to measure the distance from the rim to the tire inner treadwall. As a result, both previous strain measurement methods were identical.

Another tire deformation sensor proposed by Eom et al. [37] was made of STS303 and contains two boundaries, a fixed boundary and a sliding boundary. The sensor diaphragm diameter, height, and thickness were $8.33,300$, and $50 \mathrm{~mm}$, respectively. This sensor was installed inside a vehicle tire and connected with a surface acoustic wave transponder. The value of tire deformation was calculated from the amplitude and time consumed between radio frequency (RF) signals. The calculated deformation from the RF was very close to the actual tire deformation.

After exploiting a capacitive strain sensor with $0.013 \%$ resolution, Cao et al. [38] mounted the sensor inside a tire treadwall. The sensor's capacitance sensitivity was reported to be $76 \mathrm{fF}$ for every 10,000 microstrain. The result indicates that the generated strain increased from 0 to $8 \%$ when displacement increased in the range of $0-15 \mathrm{~mm}$ with a vertical load applied equal to $2 \mathrm{kN}$. In a further strain investigation, the authors measured the capacitance for different positions of the sensor inside the contact patch area. In each $2^{\circ}$ tire rotation, the difference in capacitance was approximately equal to $0.010 \mathrm{pF}$. This study has many advantages such as it measures the sensitivity of the sensors used that determine the error range in the results. Additionally, it determines the relation between capacitance resistance and tire strain. 


\section{TIRE STRAIN HARVESTING CHALLENGES}

Despite the many advantages of piezoelectric strain energy harvesters, some challenges may occur. This section will discuss the three main categories of challenges, including host environment, installation method, and scavenging system. These challenges are detailed in Figure 11.

\subsection{Host environment challenge}

Inner tire environment plays a significant role in the piezoelectric energy scavenging efficiency. Three main challenges were identified by reviewing background literature, including driving conditions, high temperature, and high strain. Driving conditions vary depending on numerous factors, such as vehicle speed, wide range of vibration produced, and pavement condition.

High temperature causes a depolarization affect on the piezoelectric materials. In some countries, the outside day temperature may reach $55^{\circ} \mathrm{C}$, which will be much higher inside tire values especially under working condition. The piezoelectric charge constant vary when applying a temperature range from $20^{\circ} \mathrm{C}$ to $100{ }^{\circ} \mathrm{C}$. Some piezoelectric charge constants increased when increasing temperature for instance PVDF material while other charge constants decreased when reducing the temperature such as SPC10 piezoelectric material [11].

One of the biggest challenges facing the tire strain piezoelectric energy harvesters TSPEH is high strain energy caused by tire deformation. This huge amount of available wasted energy is usually beyond the maximum strain that the piezoelectric material bender can tolerate. A regular solution is using a substrate material such as aluminum to enhance piezoelectric material strain limit. Adding an aluminum substrate to a PZT material caused an increase in the strain range to be close to a polyvinylidene fluoride PVDF material strain working range [24].

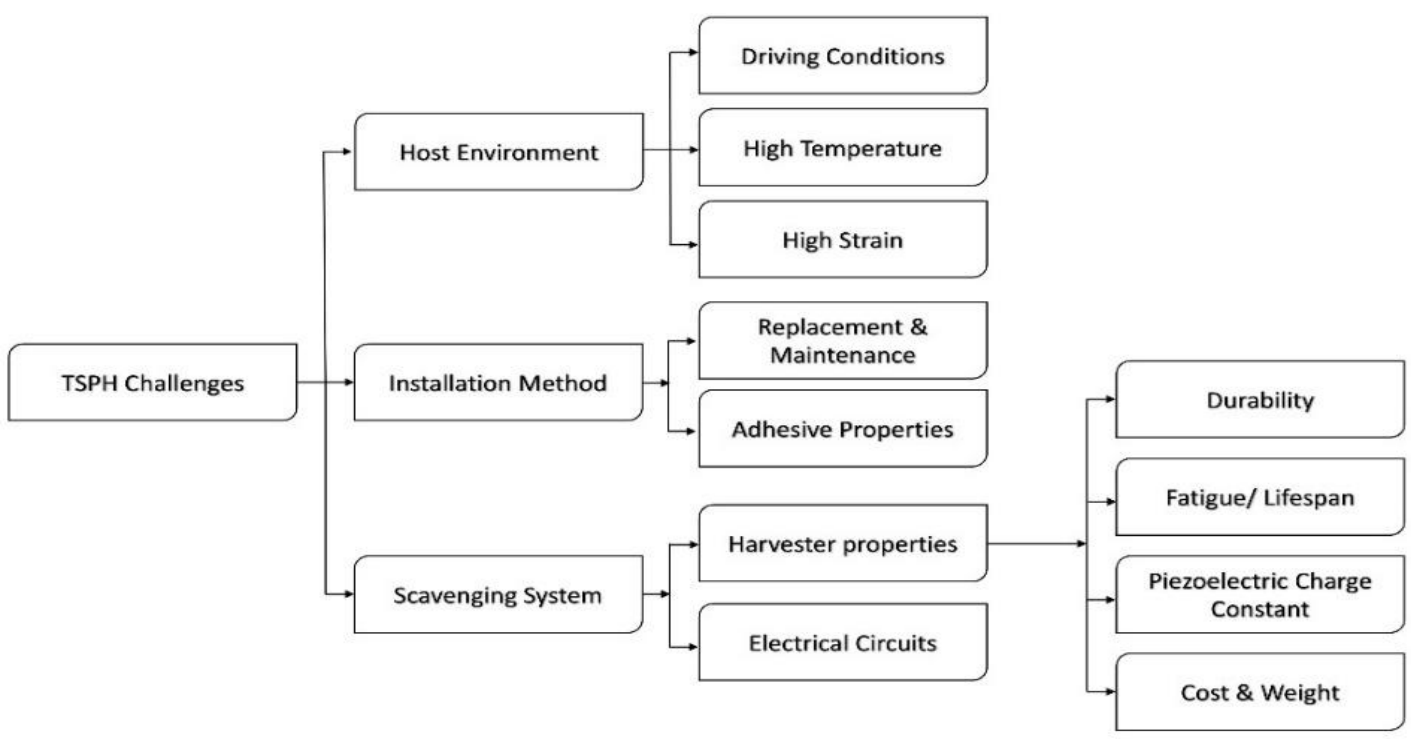

Figure 11. TSPEH available challenges

\subsection{Installation method challenge}

As discussed before, there are many installation methods. The biggest issue with the installation method is the maintenance of the system. This is because the harvester is usually stacked inside the tire, which makes it impossible to maintain the tire or the piezo bender if any damage occurs due to various reasons, such as punctures. This situation will also make it very difficult to replace the damaged piezo element, leading to financial and environmental concerns due to replacing the whole tire instead of replacing one damaged element.

The adhesive material properties might be another challenge in terms of lifespan and flexibility. Most commercial adhesives have a limited lifespan for such a high cyclic strain. Some adhesives reduce the strain to about $25 \%$ of the tire treadwall strain. Therefore, an enhanced flexible adhesive is recommended to increase the amount of strain transferred to the piezo bender element. Finally, the temperature rise might be an issue for the adhesive as it may cause unstacking of the piezo element, thus damaging the other components of the harvester. 


\subsection{Scavenging system challenge}

Two main challenges were observed in terms of the scavenging system, namely, electrical circuit challenge and harvester properties. The electrical circuit of the harvester generally consists of transducer, voltage regulator, capacitor, and transmitter. One of the main issues in the electrical circuit is the transmitting frequency per sensor. In other words, higher energy demand is required if an intelligent tire is embedded with different sensors, such as pressure, temperature, and strain sensors. Therefore, it might be challenging especially for high transfer rates.

Harvester properties might be another challenge when designing a tire strain piezoelectric energy harvesters TSPEH. There is a lack of knowledge regarding the durability of piezoelectric elements. This is because no researcher has mounted the harvester inside the tire and applied real driving conditions (real vehicle tire) for a certain mileage or number of rotations. Specifically, the researchers focused only on enhancing the maximum energy produced and neglecting a crucial part, which is system and harvester durability. In other words, how can such a system be a real replacement and a commercially available product that companies/users can trust to be mounted in their cars instead of the battery powered TPMS? No fatigue tests were conducted on the TSPEH for such a high repetitive deformation system that may cause damage or depolarization to the piezo element.

The piezoelectric charge constant can be challenging. Despite the efforts of many researchers to enhance the piezoelectric charge constant, there is a lack of measuring charge constant values and other piezo material properties after applying a cyclic strain and temperature for a certain time under real driving conditions. The whole scavenging system may cause unbalance inside tire as well, especially for high rotation speeds. This can be solved by installing a number of harvesters inside the tire in a way that prevents imbalance and increases energy production. Another challenge is connecting the components of the harvesting system inside the tire, because high rotational speed causes damage to the connections and wires.

The mass production cost for such a system should be taken into account. Through a Google search, commercial TPMS was found to cost less than 15 USD. This cost is much lower than that of battery-less TPMS system, making it uncompetitive and making the transferring method to this technology harder. This shortcoming can be improved by simplifying the battery-less TPMS system and making a cheap piezo material for mass production.

\section{CONCLUSION}

Tire deformation can be a sufficient energy source to power tire sensors, such as tire pressure monitoring system TPMS. Five shapes of tire strain piezoelectric energy harvesters TSPEHs were found in literature, namely, rectangular, square, circular, rainbow, and cymbal. The rectangular shape was commonly used owing to its higher deformation ability and design simplicity. Four categories of TSPEH were defined based on the installation method inside the vehicle tire: (i) inner tire treadwall, (ii) tire bead-rim interface, (iii) tire inner sidewall, and (iv) tire bead. Using TSPEH to power TPMS still requires improvements because of a number of challenges. TSPEH challenges were divided into three main areas, namely, host environment, installation method, and scavenging system challenges. Host environment challenges affect TSPEH directly, including driving conditions, high temperature, and high strain. Installation method challenges consist of two parts, namely, replacement and maintenance and adhesive properties section. Scavenging system challenges consist of electrical circuit, and harvester property challenges include durability, fatigue/lifespan, piezoelectric charge constant, piezo cost, and weight. For future work, a novel structure for energy harvester will be produced that can be mounted inside vehicle tire with a focus on the force direction applied to piezoelectric element. The targeted force direction is parallel to polarization direction $\left(\mathrm{d}_{33}\right)$ that generate higher energy than force direction perpendicular to polarization direction $\left(\mathrm{d}_{31}\right)$. Furthermore, the improved TSPEH will be more suitable for inside vehicle tire harvesting applications.

\section{REFERENCES}

[1] J. Lee and B. Choi, "Development of a piezoelectric energy harvesting system for implementing wireless sensors on the tires," Energy Conversion and Management, vol. 78, pp. 32-38, 2014, doi: 10.1016/j.enconman.2013.09.054.

[2] J. D. Adamson and G. P. O'brien, "System for generating electric power from a rotating tire's mechanical energy using reinforced piezoelectric materials," Goggle Patents, 2004.

[3] X. Tang, X. Wang, R. Cattley, F. Gu, and A. Ball, "Energy Harvesting Technologies for Achieving Self-Powered Wireless Sensor Networks in Machine Condition Monitoring: A Review," Sensors, vol. 18, no. 12, p. 1-39, 2018, doi: 10.3390/s18124113.

[4] S. Hwang, S. Kim, J.-Y. Pyun, and G.-R. Kwon, "Low-power TPMS Data Transmission Technique Based on Optimal Tire Condition," The Second Int. Conf. on Advances in Vehicular Systems, Technologies and Applications, pp. 29-34, 2013.

[5] K. S. Moon, H. Liang, J. Yi, and B. Mika, "Tire tread deformation sensor and energy harvester development for smart-tire applications," Sensors and Smart Structures Technologies for Civil, Mechanical, and Aerospace Systems, 2007, vol. 6529, p. 65290K. doi: 10.1117/12.721009.

[6] J. Lee, S. Kim, J. Oh, and B. Choi, “A self-powering system based on tire deformation during driving," International Journal of Automotive Technology, vol. 13, no. 6, pp. 963-969, 2012, doi: 10.1007/s12239-012-0098-0. 
[7] A. E. Kubba, M. Behroozi, O. A. Olatunbosun, C. Anthony, and K. Jiang, "Modeling of Strain Energy Harvesting in Pneumatic Tires Using Piezoelectric Transducer," Tire Science and Technology, vol. 42, no. 1, pp. 16-34, 2014, doi: 10.2346/tire.14.420102.

[8] C. R. Bowen and M. H. Arafa, "Energy Harvesting Technologies for Tire Pressure Monitoring Systems," Advanced Energy Materials, vol. 5, no. 7, pp. 14-17, 2015, doi: 10.1002/aenm.201401787.

[9] R. Van Schaijk, R. Elfrink, J. Oudenhoven, V. Pop, Z. Wang, and M. Renaud, "A MEMS vibration energy harvester for automotive applications," Proceedings Smart Sensors, Actuators, and MEMS VI, 2013, vol. 8763, pp. 1-10. doi: 10.1117/12.2016916.

[10] J. Lee, J. Oh, H. Kim, and B. Choi, "Strain-based piezoelectric energy harvesting for wireless sensor systems in a tire," Journal of Intelligent Material Systems and Structures, vol. 26, no. 11, pp. 1404-1416, 2015, doi: 10.1177/1045389X14544138.

[11] D. A. V. D. Ende, H. J. van de Wiel, W. A. Groen, and S. van der Zwaag, "Direct strain energy harvesting in automobile tires using piezoelectric PZT-polymer composites," Smart Materials and Structures, vol. 21, no. 1, p. 015011, 2012, doi: 10.1088/0964$1726 / 21 / 1 / 015011$

[12] M. S. Tamrin and M. R. Ahmad, "Simulation of adaptive power management circuit for hybrid energy harvester and real-time sensing application," International Journal of Power Electronics and Drive Systems (IJPEDS), vol. 11, no. 2, pp. 658-666, 2020, doi: 10.11591/ijpeds.v11.i2.pp658-666.

[13] A. M. M. Asry, F. Mustafa, M. Ishak, and A. Ahmad, "Power generation by using piezoelectric transducer with bending mechanism support," International Journal of Power Electronics and Drive Systems (IJPEDS), vol. 10, no. 1, pp. 562-567, 2019, doi: 10.11591/ijpeds.v10.i1.pp562-567.

[14] D. Dhasarathy, "Estimation of vertical load on a tire from contact patch length and its use in vehicle stability control," Virginia Tech, pp. 1-112, 2010.

[15] R. Esmaeeli et al., "Design, modeling, and analysis of a high performance piezoelectric energy harvester for intelligent tires," International Journal of Energy Research, vol. 43, no. 10, pp. 5199-5212, 2019, doi: 10.1002/er.4441.

[16] S. Kim, "Low power energy harvesting with piezoelectric generator," University of Pittsburgh, pp. 1-24, 2002.

[17] D. Garcia-Pozuelo, O. Olatunbosun, J. Yunta, X. Yang, and V. Diaz, “A Novel Strain-Based Method to Estimate Tire Conditions Using Fuzzy Logic for Intelligent Tires,” Sensors, vol. 17, no. 2, pp. 1-16, 2017, doi: 10.3390/s17020350.

[18] W. H. A. al Ameer, M. A. F. Al-Qaisi, and A. Al-Gizi, "Comparison between piezoelectric transformer and electromagnetic transformer used in electronic circuits," Telecommunication Computing Electronics and Control (TELKOMNIKA), vol. 18, no. 3, pp. 1567-1572, 2020, doi: 10.12928/telkomnika.v18i3.14334.

[19] R. Mohamed, M. R. Sarker, and A. Mohamed, "Modelling of a Low Frequency Based Rectangular Shape Piezoelectric Cantilever Beam for Energy Harvesting Applications," Indonesian Journal of Electrical Engineering and Computer Science, vol. 12, no. 1, pp. 290-295, 2018, doi: 10.11591/ijeecs.v12.i1.pp290-295.

[20] D. A. V. D. Ende, W. A. Groen, and S. V. D. Zwaag, "Robust piezoelectric composites for energy harvesting in high-strain environments," Journal of Intelligent Material Systems and Structures, vol. 24, no. 18, pp. 2262-2269, 2013, doi: $10.1177 / 1045389 X 12462646$.

[21] J. V. Randeraat and R. E Setterington, "Piezoelectric Ceramics Aplication Book," Eindhoven, Netherlands: NV Philips' Gloeilampenfabrieken, 1974

[22] T. Merdjana and A. Chaabi, "Study and simulation with VHDL-AMS of the electrical impedance of a piezoelectric ultrasonic transducer," International Journal of Power Electronics and Drive Systems (IJPEDS), vol. 10, no. 2, pp. 1064-1071, 2019, doi: 10.11591/ijpeds.v10.i2.pp1064-1071

[23] C. Daimler, “Apollo IST-2001-34372: intelligent tyre for accident-free traffic,” Eur. Comm. Inform. Society Tec, vol. 1, pp. 1-64, 2005

[24] N. Makki and R. Pop-Iliev, "Pneumatic tire-based piezoelectric power generation," Proceedings Active and Passive Smart Structures and Integrated Systems, 2011, vol. 7977, pp. 1-13. doi: 10.1117/12.880636.

[25] R. Esmaeeli et al., "Optimization of a Rainbow Piezoelectric Energy Harvesting System for Tire Monitoring Applications," ASME 12th International Conference on Energy Sustainability, 2018, vol. 51418, pp. 1-8, doi: 10.1115/ES2018-7496.

[26] H. Aliniagerdroudbari, R. Esmaeeli, S. R. Hashemi, M. Alhadri, W. Zakri and S. Farhad, "A piezoelectric sandwich structure for harvesting energy from tire strain to power up intelligent tire sensors," IEEE Power and Energy Conference at Illinois (PECI), 2019, pp. 1-7, doi: 10.1109/PECI.2019.8698908

[27] F. Khameneifar and S. Arzanpour, "Energy Harvesting From Pneumatic Tires Using Piezoelectric Transducers," Smart Materials, Adaptive Structures and Intelligent Systems, vol. 43314, pp. 331-337, 2009, doi: 10.1115/SMASIS2008-426.

[28] N. Makki and R. Pop-Iliev, "Piezoelectric power generation for sensor applications: design of a battery-less wireless tire pressure sensor," Smart Sensors, Actuators, and MEMS V, vol. 8066, pp. 1-10, 2011, doi: 10.1117/12.887112.

[29] N. Makki and R. Pop-Iliev, "Piezoelectric power generation in automotive tires," Proceedings of the Smart Materials \& Structures/NDT in Aerospace/NDT in Canada, 2011, pp. 1-10.

[30] N. Makki and R. Pop-Iliev, "Battery-and wire-less tire pressure measurement systems (TPMS) sensor," Microsystem Technologies, vol. 18, no. 7-8, pp. 1201-1212, 2012, doi: 10.1007/s00542-012-1480-6.

[31] R. Esmaeeli et al., "A Rainbow Piezoelectric Energy Harvesting System for Intelligent Tire Monitoring Applications,” Journal of Energy Resources Technology, vol. 141, no. 6, Jun. 2019, doi: 10.1115/1.4042398.

[32] D. Maurya et al., "Energy harvesting and strain sensing in smart tire for next generation autonomous vehicles," Applied Energy, vol. 232, pp. 312-322, 2018, doi: 10.1016/j.apenergy.2018.09.183.

[33] Y. Hu, C. Xu, Y. Zhang, L. Lin, R. L. Snyder, and Z. L. Wang, "A Nanogenerator for Energy Harvesting from a Rotating Tire and its Application as a Self-Powered Pressure/Speed Sensor,” Advanced Materials, vol. 23, no. 35, pp. 4068-4071, 2011, doi: 10.1002/adma.201102067

[34] Z. Yang, S. Zhou, J. Zu, and D. Inman, "High-Performance Piezoelectric Energy Harvesters and Their Applications,” Joule, vol. 2, no. 4, pp. 642-697, 2018, doi: 10.1016/j.joule.2018.03.011.

[35] J. Yunta, D. G. Pozuelo, V. Diaz, and O. Olatunbosun, "Influence of camber angle on tire tread behavior by an on-board strainbased system for intelligent tires," Measurement, vol. 145, pp. 631-639, 2019, doi: 10.1016/j.measurement.2019.05.105.

[36] D. Garcia-Pozuelo et al., "Development and experimental validation of a real-time analytical model for different intelligent tyre concepts," Vehicle System Dynamics, vol. 57, no. 12, pp. 1970-1988, 2019, doi: 10.1080/00423114.2019.1566560.

[37] J. Eom, H. Lee, and B. Choi, "A study on the tire deformation sensor for intelligent tires," International Journal of Precision Engineering and Manufacturing, vol. 15, no. 1, pp. 155-160, 2014, doi: 10.1007/s12541-013-0319-0.

[38] S. Cao, S. Pyatt, C. Anthony, A. I. Kubba, A. E. Kubba, and O. Olatunbosun, "Flexible Bond Wire Capacitive Strain Sensor for Vehicle Tyres," Sensors, vol. 16, no. 6, pp. 1-17, 2016, doi: 10.3390/s16060929. 


\section{BIOGRAPHIES OF AUTHORS}
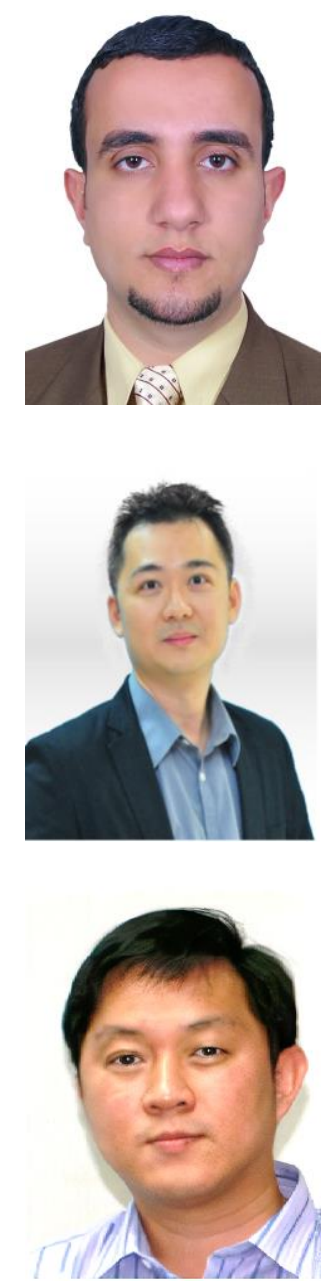

Ibrahim Ali Hameed Al-Najati (D) 8 SC P received his B.S.c degree in Mechanical Engineering from Al Mustansiriya University Baghdad, Iraq in 2011 and M.S.c degree in Mechanical Engineering (Distinction grade) from University of Hertfordshire, Hatfield, United Kingdom, in 2016. He is currently pursuing the Ph.D. degree in Mechanical Engineering at Universiti Sains Malaysia (USM), Pulau Pinang, Malaysia. He is a Lecturer at Southern Technical University, Iraq since 2016. His research interest includes the development of piezoelectric materials to be used as transducers especially in vehicle tires, energy storage and renewable energy. Mr. Ibrahim's awards and honors include full M.S.c. sponsor ship award from HCED, Iraq, Prime Minister Office (Jan 2015), full Ph.D. sponsor ship award from Southern Technical University, Iraq (March 2020). He can be contacted at email: ibrahim.hameed@student.usm.my.

Keng Wai Chan (iD 8d SC P received his BEng (Hons) in Mechanical Engineering from Universiti Sains Malaysia, and DPhil in Engineering Science from University of Oxford, UK. He is currently a lecturer at School of Mechanical Engineering, Universiti Sains Malaysia. His research interests include refrigeration and air conditioning, renewable energy, and sustainable building design. He is a Professional Engineer registered under the Board of Engineer Malaysia (BEM) and a Green Building Index Facilitator (GBIF) registered under the Greenbuildingindex Sdn Bhd. He is also a committee member of the Malaysia Green Building Council (malaysiaGBC) Northern Chapter, an NGO to promote sustainable building in Malaysia. He can be contacted at email: kengwai.chan@usm.my.

Swee-Yong Pung (D) If SC $\mathrm{P}$ received his B.Eng in Materials Engineering (first class honor) from Universiti Sains Malaysia in 1998. He joined S.E.H. (M) Sdn. Bhd., a silicon wafer manufacturer, as R\&/Materials Characterization engineer. He did his M.Tech (Materials Science) from University of Malaya in part-time basic and successfully completed his study in 2002. He joined a RD company, InventQjaya (M) Sdn. Bhd. in 2003 as Laboratory Supervisor. He was the technical head in charged of developing smart window based on polymer stabilized Cholesteric textures technique. In 2006, he received scholarship from USM under Academic Staff Training Scheme (ASTS) to further his PhD study. He obtained his doctoral degree from the University of Nottingham, United Kingdom in 2010 for his work on synthesis and characterization of $\mathrm{ZnO}$ nanowires. After completion of his study, he joined Universiti Sains Malaysia as lecturer till now. His current research interests are related to semiconductor nanomaterials particularly on $\mathrm{ZnO}$, WOx and $\mathrm{MnO} 2$ as well as phosphor materials. He can be contacted at email: sypung@usm.my. 